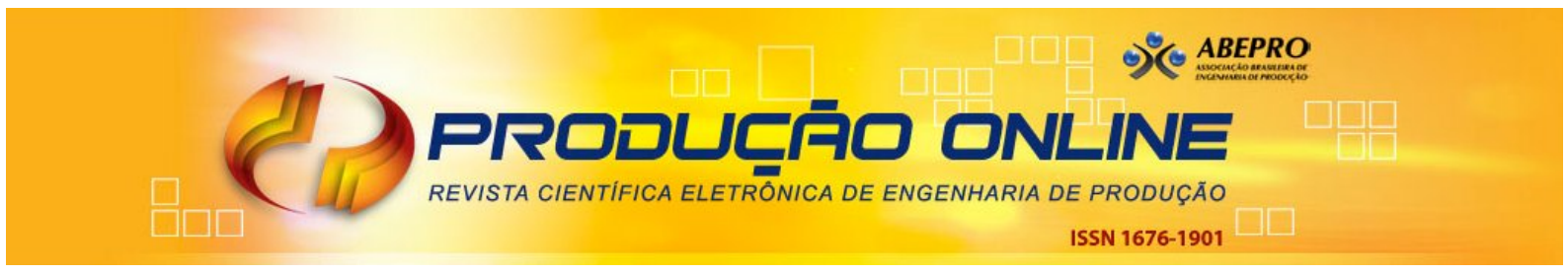

\title{
MODELO MULTICRITÉRIO DE APOIO À DECISÃO CONSTRUTIVISTA PARA AVALIAÇÃO DE DESEMPENHO DO TRADE MARKETING: UM CASO ILUSTRADO NO SETOR FARMACÊUTICO
}

\section{MCDA-C MODEL FOR TRADE MARKETING PERFORMANCE EVALUATION: AN ILLUSTRATED CASE IN THE PHARMACEUTICAL SECTOR}

\author{
André Andrade Longaray* E-mail: longaray@yahoo.com.br \\ Leonardo Ensslin** E-mail: leonardoensslin@gmail.com \\ Sandra Ensslin*** E-mail: sensslin@gmail.com \\ Ademar Dutra** Email: ademar.dutra@unisul.br \\ Paulo Roberto da Silva Munhoz* E-mail: paulorsmunhoz@hotmail.com \\ *Universidade Federal do Rio Grande (FURG), Rio Grande, RS \\ **Universidade do Sul de Santa Catarina (UNISUL), Florianópolis, SC \\ ***Universidade Federal de Santa Catarina (UFSC), Florianópolis, SC
}

\begin{abstract}
Resumo: Desde sua introdução, no início dos anos 1990, o conceito de trade marketing tem ocupado relevante papel nas empresas e em seus canais de distribuição, tendo como foco a consolidação da estratégia de marketing no ponto de venda. Na prática, um dos principais limitantes de seu uso mais generalizado tem sido a ausência de instrumentos gerenciais que permitam visualizar as consequências do trade marketing nos objetivos da organização. Dentro desse contexto, este trabalho expõe o emprego da metodologia multicritério de apoio à decisão construtivista como instrumento de intervenção no estudo de caso realizado em uma indústria farmacêutica, com o objetivo de desenvolver um modelo personalizado de avaliação para auxiliar a gestão de trade marketing por meio da identificação, organização, mensuração, e integração dos fatores considerados pelo gestor como necessários e suficientes para sua gestão. O processo de construção do modelo ocorreu de forma interativa por meio de entrevistas com os decisores. O modelo construído permitiu aos executivos incorporarem aspectos singulares da empresa e do ambiente, ampliando as possibilidades de avaliação de desempenho do trade marketing organizacional.
\end{abstract}

Palavras-Chave: Analise de decisão multicritério. Trade marketing. Avaliação de desempenho.

Abstract: Since its introduction in the early 1990s, trade marketing has played a significant role in companies and their distribution channels, focusing on the consolidation of marketing strategy at the point of purchase. In practice, one of the main obstacles for a more widespread use of trade marketing has been the lack of management tools allowing visualisation of the consequences of trade marketing in the organisation's objectives. This study shows the use of the Multi-Criteria Decision AidingConstructivist methodology model as an instrument of intervention in a case study conducted in a pharmaceutical company. A customised evaluation model was built interactively by interviewing decision makers to identify, organise, measure, and integrate those factors considered necessary and sufficient for the management of trade marketing. The constructed model enables executives to incorporate unique aspects of the company and the environment, expanding the possibilities for performance evaluation of trade marketing in the organisation.

Keywords: Multi Criteria Decision Analysis. Trade marketing. Performance evaluation. 


\section{INTRODUÇÃO}

A produção industrial brasileira vem crescendo significativamente nos últimos anos. Dados do Instituto Brasileiro de Geografia e Estatística (IBGE) indicam que, comparativamente, no período entre agosto de 2010 e agosto de 2011, ela cresceu 1,8\%. Na análise, realizada em vinte e sete setores da indústria, dezesseis apresentaram aumento na produção. Entre esses, o setor farmacêutico foi um dos que mais influenciaram o resultado final, exibindo crescimento acumulado de 3,9\% (IBGE, 2012).

Hoje, o Brasil figura como sétimo maior mercado da indústria farmacêutica mundial. Isso se deve a ampliação da população da classe C, que representa $42 \%$ dos consumidores do setor no país e, ao acréscimo das exportações, que em 2010 chegou a 1,7 bilhões de dólares (ABRADILAN, 2015).

Ao mesmo tempo em que se mostra extremamente favorável, o atual panorama do setor farmacêutico nacional também expõe uma série de desafios a serem superados. Dentre esses, destacam-se o aumento da concorrência causado pela imigração de fábricas de laboratórios de outros países, a necessidade da constante adequação às normas dos órgãos regulatórios de saúde e a mudança de perfil dos consumidores, que se tornaram mais exigentes na medida em que conquistaram o direito de escolha.

Nesse cenário, caracterizado pelo dinamismo das relações e pela maior oferta do que a procura, as indústrias farmacêuticas brasileiras têm procurado adotar novas estratégias na busca de uma maior competividade. Diante da gama de possibilidades, um número significativo de empresas desse segmento de mercado tem optado por incorporar o trade marketing às suas práticas de gestão.

O trade marketing representa o conjunto de esforços junto aos canais de distribuição para incrementar a relação entre marca, pontos-de-venda e consumidores. O objetivo principal é o fortalecimento da marca, a criação de interesse dos canais de venda pela sua comercialização e a atração da preferência dos consumidores aos quais o produto é direcionado.

Considerada uma prática relativamente recente, com surgimento por volta do início dos anos 1990, o trade marketing ainda se encontra em estágio de desenvolvimento como ferramenta de gestão. Uma das questões emergentes se 
refere às formas pelas quais as atividades do trade marketing podem ser gerenciadas e evidenciadas suas contribuições para a empresa.

Como o departamento de trade marketing atua de forma integrada com os departamentos de marketing e de vendas, existe certa dificuldade em evidenciar e mensurar qual o grau de participação das atividades de trade marketing nos resultados obtidos pela empresa.

Enquanto as ações de marketing podem ser medidas pelo valor de mercado da marca, pelo número de canais de distribuição e pela quantidade de consumidores do produto; e, as ações de vendas podem ser mensuradas pela quantidade efetiva de produtos comercializados e pela fatia do mercado que a marca detém; as ações do trade marketing não possuem métricas tão claras, pois se baseiam em atividades de relacionamento com distribuidores, pontos de venda e clientes.

Inserido nesse contexto, o presente trabalho tem por objetivo 0 desenvolvimento de um modelo para auxiliar os gestores de uma indústria farmacêutica na identificação, operacionalização e mensuração de critérios que permitam a avaliação do desempenho das atividades do departamento de trade marketing. Levando-se em consideração, a complexidade da situação, as múltiplas variáveis abrangidas, os interesses conflitantes envolvidos, e a necessidade de ajudar seus gestores a entender o contexto será utilizada a Metodologia Multicritério em Apoio à Decisão Construtivista (MCDA-C) por sua potencialidade em lidar com tais contextos. (De Moraes et al., 2010; Lacerda et al., 2011a; Lacerda et al., 2011b; Rosa et al., 2012).

O presente artigo está organizado em seis seções. Exposta esta seção introdutória, a seção 2 discorre sobre o conceito de trade marketing e a problemática de seus indicadores. A seção 3 expõe a metodologia multicritério de apoio à decisão construtivista. Na sequência, a seção 4 apresenta os procedimentos metodológicos da pesquisa. A seção 5 descreve a construção do modelo de avaliação do estudo de caso. Por fim, a seção 6 tece as considerações finais da pesquisa.

\section{O TRADE MARKETING E A PROBLEMÁTICA DOS INDICADORES}

O conceito de trade marketing surgiu na última década do século $\mathrm{XX}$, impulsionado pela inversão da lógica de consumo predominante até então. Com o Revista Produção Online, Florianópolis, SC, v.16, n. 1, p. 49-76, jan./mar. 2016. 
fim das fronteiras entre mercados, propiciado em boa parte pelos avanços tecnológicos, o comércio tradicional passou de uma perspectiva em que a procura era maior que a oferta, para uma situação de demanda excedente (HUBER et al., 2012).

Em um cenário em que a visibilidade dos produtos e serviços oferecidos, a rapidez no processo logístico e a desoneração de custos operacionais tornaram-se aspectos vitais para a sobrevivência das empresas na nova economia, cresceu também a importância dos canais de distribuição: distribuidores, atacadistas e varejistas.

Nascia, então, a expressão "trade marketing". Empregada primeiramente pela companhia norte-americana Colgate Palmolive, foi utilizada para referir à integração das funções dos departamentos de vendas e marketing da empresa, com a finalidade de estreitar as relações entre a fabricante e seus distribuidores.

O objetivo dessa integração seria estabelecer procedimentos para reconhecer os hábitos e necessidades dos consumidores de um canal de distribuição e delinear estratégias para transformar essa clientela em potenciais compradores da marca. Como resultado, novas ações de preço, localização, exposição, inovação, embalagem, sortimento e merchandising poderiam ser desenvolvidas (SPONTON, 2008).

As tentativas iniciais de operacionalização das táticas de trade marketing se deram com a alocação de vendedores da área comercial dedicados especialmente a clientes-chave do negócio. Essa forma de atuação logo progrediu para a designação de executivos de marketing que teriam a responsabilidade de gerenciar 0 desempenho de seus clientes-chave. Hoje, um significativo número de organizações tem optado pela adoção de um departamento específico de trade marketing (ALMEIDA et al., 2012).

Tal evolução se justifica especialmente no Brasil, pelo crescimento do canal de distribuição do varejo, ou como este é usualmente chamado, o ponto de venda (PDV). De acordo com Silva Neto et al. (2011), pesquisa realizada pela instituição POPAI (Point of Purchase Advertising International) em 2007 revelou que, no Brasil, $85 \%$ das compras são decididas no ponto de venda, enquanto que no restante do mundo, este percentual não ultrapassa $7 \%$. 
Uma questão controversa, no entanto, diz respeito à avaliação da contribuição dada pelo departamento de trade marketing aos resultados das empresas. Se existem métricas delineadas e tradicionalmente utilizadas para as áreas de marketing e vendas (KOTLER et al., 2013), o mesmo não acontece com a área de trade marketing.

Estudos recentes têm discutido sobre a dificuldade de estabelecer indicadores próprios para as ações de trade marketing (CASTILLO, 2000; LABAJO e CUESTA, 2004; ALVAREZ, 2008; SILVA et al., 2011; ALMEIDA et al., 2012) que não se sobreponham aos já utilizados para avaliar os resultados dos departamentos de marketing e vendas (MOTTA et al., 2008; COBRA e TALARICO, 2008).

Em um estudo no setor farmacêutico, segmento em que se insere a empresa objeto de estudo desta pesquisa, Huber et al. (2012) constataram a inexistência de indicadores padrão para avaliar uma indústria do setor farmacêutico de remédio com venda livre, os OTC (Over The Counter).

Dentro desse panorama, este trabalho utiliza a metodologia multicritério de apoio à decisão para a construção de um modelo de avaliação de desempenho das atividades de trade marketing de uma indústria farmacêutica com um número significativo de pontos de venda distribuídos pelo Brasil.

\section{METODOLOGIA MULTICRITÉRIO DE APOIO À DECISÃO CONSTRUTIVISTA}

A Metodologia Multicritério de Apoio à Decisão construtivista (MCDA-C) é uma abordagem oriunda da escola europeia de decisão (ROY, 1996). Ela se baseia no construtivismo para proporcionar entendimento e aprendizado sobre o contexto decisório e, em métodos de agregação matemática de critérios por subordinação de síntese, para transformar julgamentos qualitativos em quantitativos e sintetizar a multiplicidade de critérios na forma de uma equação geral (ROY, 2005).

O construtivismo parte do pressuposto que o homem responde aos estímulos externos agindo sobre eles para construir e organizar o seu próprio conhecimento. Os eventos são reais, mas a interpretação que se dá aos mesmos é eminentemente subjetiva, variando assim de pessoa a pessoa. Desta forma um determinado evento pode ser um problema para uma dada pessoa ou uma oportunidade para outra (ROY, 2005; LONGARAY et al, 2014)). 
Assim, na MCDA construtivista, pesquisadores estimulam os decisores a participarem ativamente na determinação do problema e identificação de suas causas, bem como na formulação das possibilidades de atuação sobre a situação percebida como problemática. É um processo de aprendizagem em que a interação entre pesquisador e decisor pode ser feita por meio da utilização de abordagens de estruturação de problemas (ROSENHEAD, 1989). O resultado prático é a identificação dos critérios, a elaboração da estrutura hierárquica de valores e a formulação das recomendações (BANA E COSTA e VANSNICK, 1995).

Quanto ao método matemático utilizado, a abordagem da subordinação de síntese, sobreclassificação, ou ainda, outranking, tem origem na escola francesa da decisão (ROY, 1996). Baseia-se na ideia de uma relação de subordinação entre as possíveis ações para a decisão, por meio de limiares. Tais limiares têm a função de diminuir a dificuldade normalmente encontrada pelo decisor em arbitrar valores numéricos precisos sobre suas preferências (ROY, 2010).

São exemplos de métodos de sobreclassificação o ELECTRE - Elimination et Choix Traduisant la Réalité, criado por Roy (1996), que usa critérios de peso para a construção de matrizes de concordância e de discordância, fazendo a comparação com pseudocritérios através de relações hierárquicas nebulosas, considerando aspectos de aceitação, de rejeição ou estimando a credibilidade da informação; o PROMETHEE - Preference Ranking Organization Method for Enrichment Evaluations, que constrói uma pré-ordenação parcial das alternativas, utilizando dois fluxos de hierarquização, um positivo, que mostra como uma alternativa se sobressai sobre a outras, e outro negativo, que mostra como essa alternativa é sobrepujada por outras; e o MACBETH - Measuring Attractiveness by a Categorical Based Evaluation Technique, que permite transformar escalas ordinais em cardinais tomando por base juízos absolutos sobre a diferença de atratividade entre duas alternativas (ENSSLIN, MONTIBELLER e NORONHA, 2001; LONGARAY et al, 2014).

Para operacionalizar o processo de apoio à decisão, Roy $(1996,2005)$, Galves (2005) e Ensslin et al. (2010) referem que o emprego da abordagem MCDA construtivista deve seguir três etapas: estruturação, avaliação e recomendações. (De MORAES et al., 2010; LACERDA et al., 2011a; LACERDA et al., 2011b; ROSA et al., 2012).

Revista Produção Online, Florianópolis, SC, v.16, n. 1, p. 49-76, jan./mar. 2016. 


\subsection{Etapa de estruturação}

A etapa de estruturação trata da formulação do problema e busca identificar, caracterizar e organizar os fatores considerados relevantes no processo de apoio à decisão. Ela ocorre de forma interativa e dinâmica, proporcionando o debate e aprendizado (BANA E COSTA, 1993).

Nesse processo, espera-se que os decisores identifiquem um conjunto de critérios que permitam comparar entre si diferentes níveis de desempenho. Segundo Roy (2010), o conjunto de critérios deve satisfazer às condições de exaustividade (descrição do problema levando em conta todos os aspectos relevantes), de coesão (definição dos critérios de minimização e de maximização) e não redundância (exclusão de critérios que avaliam características já analisadas por outro critério).

No intuito de facilitar o procedimento de entendimento e organização do contexto decisório emprega-se nesta etapa algum método soft de estruturação de problemas (ROSENHEAD, 1989). Depois de identificados, os critérios devem ser organizados em forma de hierarquia ou árvore, onde o nível mais alto de um critério é decomposto em níveis mais detalhados (LONGARAY et al., 2015).

No nível hierárquico mais inferior de cada critério tem-se seu descritor. Um descritor é uma escala ordinal que representa os possíveis níveis de impacto em que se pode avaliar o desempenho de uma possível ação potencial em um determinado critério, segundo as preferências dos decisores (ROY, 2010). Todo descritor deve possuir, dentre seus níveis de impacto, dois níveis de referência. Um nível denominado Neutro, que corresponde ao desempenho abaixo do qual o decisor considera comprometedor em cada critério e, um nível designado de Bom, relativo ao nível de desempenho acima qual do decisor considera como desempenho excelente. Entre o Neutro e o Bom o desempenho é considerado normal ou de mercado. (DE MORAES, et al., 2010; LACERDA, et al., 2011a; LACERDA, et al., 2011b; ROSA et al., 2012).

\subsection{Etapa de avaliação}

$\mathrm{Na}$ etapa de avaliação de um modelo MCDA-C aplica-se um dos métodos matemáticos de subordinação de síntese existentes e procede-se a construção da Revista Produção Online, Florianópolis, SC, v.16, n. 1, p. 49-76, jan./mar. 2016. 
escala de preferência local dos critérios (relações de preferência entre os níveis de um descritor), a determinação das taxas de compensação entre critérios (relação de preferência entre os critérios de um mesmo nível hierárquico) e a identificação do perfil de desempenho das ações potenciais (agregação de todos os níveis de todos os critérios em um modelo aditivo).

Com todas as relações de preferência do modelo estabelecidas é possível mensurar o desempenho de uma determinada ação potencial (uma alternativa) tanto localmente (desempenho em um critério) quanto globalmente (desempenho em todos os critérios).

$\mathrm{Na}$ operacionalização do processo para o apoio à decisão descrito neste artigo, foi utilizado o método MACBETH - Measuring Attractiveness by a Categorical Based Evaluation Technique (BANA E COSTA e VANSNICK, 1995). No MACBETH, mediante a comparação para a par da atratividade das alternativas, são atribuídos níveis de preferências entre os critérios. Dadas duas alternativas, o decisor deve indicar qual a mais atrativa e qual o grau desta atratividade, em uma escala semântica que tem correspondência com uma escala ordinal ( 0 ”indiferente, $1 \equiv$ diferença de atratividade muito fraca, 2 diferença de atratividade fraca, $3 \equiv$ diferença de atratividade moderada, $4 \equiv$ diferença de atratividade forte, $5 \equiv$ diferença de atratividade muito forte e 6 = diferença de atratividade extrema).

Deve-se levar em consideração que os números da escala não tem significado matemático. Eles atuam como indicadores semânticos da categoria de diferença de atratividade atribuída ao par de alternativas (ENSSLIN et al., 2010).

Em uma perspectiva matemática, o método MACBETH é constituído por quatro problemas de minimização (Mc) de programação linear (PPL), resolvidos sequencialmente (BANA E COSTA e VANSNICK, 1995): PPL1 - Problema Mc1: realiza a análise de consistência cardinal; PPL2 - Problema Mc2: responsável pela construção da escala de valor cardinal; e PPL3 e PPL4 - Problemas Mc3 e Mc4: revelam fontes de inconsistência.

As relações matemáticas podem ser obtidas por meio do software $M$ MACBETH, que implementa computacionalmente o método. Nele são feitas as análises de julgamento do decisor. Por programação linear, é sugerida uma escala de notas e os intervalos em que elas podem variar sem tornar o problema inconsistente. Quando da transformação das escalas ordinais (descritores) em Revista Produção Online, Florianópolis, SC, v.16, n. 1, p. 49-76, jan./mar. 2016. 
cardinais, o M-MACBETH permite a fixação dos intervalos dos níveis Neutro (0) e Bom (100), além de proceder a normalização da escala (LONGARAY et al, 2015).

No que tange à determinação das taxas de compensação do modelo (constantes de escala), o M-MACBETH emprega o mesmo procedimento de comparação par a par. Deve-se salientar que, nas relações de preferência entre critérios, é necessária a ordenação de possíveis Ações (Al) que impactem nesses critérios e a inclusão de uma ação fictícia (A0) na matriz para, então, proceder à cardinalização dos mesmos (BANA E COSTA e VANSNICK, 1995).

Uma das possibilidades de ordenação dos critérios é a utilização da matriz de Roberts (1979). Para preencher as colunas da matriz, são simuladas possíveis ações que impactam nos critérios de um mesmo nível hierárquico e solicitado ao decisor que atribua o valor "1" a uma ação que predomine sobre outra e o valor "0" a uma ação que seja dominada pela outra. O somatório de cada linha indica, segundo as preferências do decisor, o ordenamento das ações (ENSSLIN et al., 2010).

Com a determinação das escalas de preferências locais dos critérios e das taxas de compensação entre esses critérios, é possível proceder à transformação do modelo de múltiplos critérios em um modelo de critério único (avaliação global) (BANA E COSTA, DE CORTE e VANSNICK, 2005).

\subsection{Etapa de recomendações}

A fase de recomendações da MCDA construtivista tem por objetivo apoiar o decisor no uso do modelo construído ao longo do processo de apoio à decisão. Como a abordagem empregada possui o viés do construtivismo, não pretende prescrever orientações, apenas auxiliar o decisor na construção (desenvolvimento) e análise de possíveis alternativas e no entendimento de suas consequências. A operacionalização desse processo pode ser realizada de várias formas. Dentre as possíveis, Ensslin et al. (2010), De Moraes et al. (2010), Lacerda al. (2011a), sugerem a identificação do desempenho de cada escala cardinal para conhecer a performance específica em determinado critério; o estabelecimento de estratégias diferentes para identificar o impacto na avaliação global de desempenho; a análise da relação custo versus benefício na implementação de uma estratégia; o estabelecimento de prioridades nas estratégias e ações que se pretende implantar 
por meio dos objetivos com maior grau de contribuição (taxas de compensação); e, a avaliação do desempenho em cada nível (estratégico, tático e operacional).

\section{PROCEDIMENTOS METODOLÓGICOS DA PESQUISA}

A presente seção expõe o delineamento metodológico da pesquisa. Classifica o trabalho quanto à finalidade, natureza, fonte de coleta de dados, lógica de pesquisa, abordagem metodológica e o instrumento de intervenção empregado.

No que tange a sua finalidade, a pesquisa enquadra-se como um estudo exploratório. De acordo com Gil (2002), estudos exploratórios tem o objetivo principal de desenvolver ideias e conduzir a procedimentos relativamente sistemáticos para a obtenção de observações empíricas, bem como possibilitar a identificação das relações entre os fenômenos estudados. Tal perspectiva se alinha com os objetivos desta pesquisa.

O objetivo geral consiste em construir um modelo personalizado para avaliar o desempenho do departamento de trade marketing de uma indústria farmacêutica com vista a promover a competitividade organizacional. Os objetivos específicos para a consecução desta pesquisa são: explicitar os atores e em particular os decisores em nome de quem os valores e preferências serão determinados; identificar os critérios que atendam as metas do trade marketing da empresa; elaborar a estrutura hierárquica de critérios; construir escalas ordinais de cada critério; transformar as escalas ordinais em escalas cardinais; estabelecer as taxas de compensação entre os critérios; construir o modelo de agregação dos critérios; representar o perfil de desempenho de possíveis ações no modelo construído; e identificar e analisar elementos que mereçam ações de aperfeiçoamento.

Quanto à sua natureza, esta pesquisa se caracteriza como um estudo de caso. O estudo de caso foi realizado em uma indústria farmacêutica de grande porte, localizada no Estado do Rio Grande do Sul, e que atua nos segmentos OTC (medicamentos isentos de prescrição médica), fitoterápicos, cosméticos e medicamentos com prescrição médica. A empresa conta com um portfólio de mais de 50 produtos e 100 apresentações e uma rede de 40 distribuidores que atinge 40 mil pontos de venda em todo o Brasil. O faturamento da empresa em 2011 ficou 
próximo a $\mathrm{R} \$ 62$ milhões de reais. Seu quadro funcional conta com cerca de 1.300 colaboradores.

Como fonte de coleta de dados, o trabalho emprega entrevistas, análise documental e pesquisa bibliográfica (GIL, 2002). Foram realizadas entrevistas não estruturadas para a obtenção dos dados primários e o levantamento de documentos e pesquisa bibliográfica como fonte de dados secundários.

A lógica de pesquisa adotada é mista. Ela é indutiva na fase de estruturação do modelo, onde não se parte de princípios, mas sim dos fatos resultantes de observações e da inserção na realidade. Assume a perspectiva dedutiva na fase de avaliação, pois a partir do modelo construído estabelecem-se conclusões particulares (GIL, 2002). Por fim, a lógica é indutiva na fase de elaboração das recomendações, uma vez que as análises são feitas a partir do entendimento adquirido no decorrer de todo o desenvolvimento do modelo.

A abordagem metodológica do trabalho é quali-quantitativa. Gil (2002) defende a ideia de combinar métodos quantitativos e qualitativos, com intuito de proporcionar uma base contextual mais rica para interpretação e validação dos resultados de uma pesquisa. Sob essa ótica, o presente estudo é quantitativo na etapa de avaliação e qualitativo nas etapas de estruturação e de elaboração das recomendações.

O instrumento de intervenção empregado na pesquisa é a MCDA construtivista. A opção pelo emprego dessa metodologia de apoio à decisão se deve à sua capacidade de proporcionar condições de identificação, operacionalização e mensuração dos critérios que representam a percepção dos decisores em relação às possibilidades de avaliar o desempenho das atividades de trade marketing da empresa. Viabiliza, ainda, a incorporação de sugestões de melhoria em alternativas com um perfil de desempenho incompatível com o esperado.

\section{CONSTRUÇÃO DO MODELO DE AVALIAÇÃO DE DESEMPENHO}

Esta seção descreve o uso da MCDA construtivista como instrumento de intervenção no processo de construção do modelo de avaliação de desempenho para a indústria farmacêutica objeto do estudo de caso. Para tanto, discorre sobre as fases de estruturação, de avaliação e de elaboração das recomendações. 


\subsection{Etapa de estruturação}

O primeiro passo da etapa consistiu no emprego de uma abordagem soft de estruturação de problemas. Foi utilizada a técnica de mapeamento cognitivo (EDEN, 2004) com o objetivo de auxiliar o decisor a expandir seu entendimento sobre o contexto decisório. Para a construção do mapa cognitivo do estudo de caso foram observados os procedimentos recomendados por Eden e Ackermann (2006).

Uma entrevista inicial com os executivos que solicitaram o apoio à decisão permitiu a identificação do decisor, dos stakeholders (intervenientes e facilitadores) e agidos no contexto decisório. Ficou estabelecido pelos dirigentes que o decisor deveria ser o coordenador nacional de trade marketing da indústria farmacêutica objeto do estudo de caso. O gerente nacional de vendas e o gerente nacional de marketing da empresa participaram como intervenientes. Os autores deste artigo atuaram como facilitadores. Os distribuidores, atacadistas e varejistas foram caracterizados como agidos do apoio à decisão, ou seja, aqueles atores que não atuam na decisão, mas são afetados direta ou indiretamente pelos resultados da mesma.

Foram realizadas três entrevistas abertas não estruturadas com o decisor e os intervenientes. A duração aproximada de cada uma das entrevistas foi de duas horas. Ao final de uma entrevista, o esboço do mapa era submetido à legitimação dos participantes.

A viabilização da construção do mapa cognitivo durante a realização das entrevistas decorreu do uso do software Decision Explorer (BRIGHTMAN, 2002), uma ferramenta computacional que auxilia na elaboração gráfica dos mapas. Com isso, foi possível nomear os conceitos e seus opostos psicológicos, estabelecer o sentido das relações de influência entre eles, agrupa-los em clusters (áreas de preocupações do decisor), de um modo interativo, no momento em que as entrevistas ocorreram (EDEN, 2004).

A Figura 1 apresenta um recorte do mapa cognitivo do caso em estudo, em que é delineado o cluster "distribuição": 
Figura 1 - Recorte do mapa cognitivo para o cluster distribuição

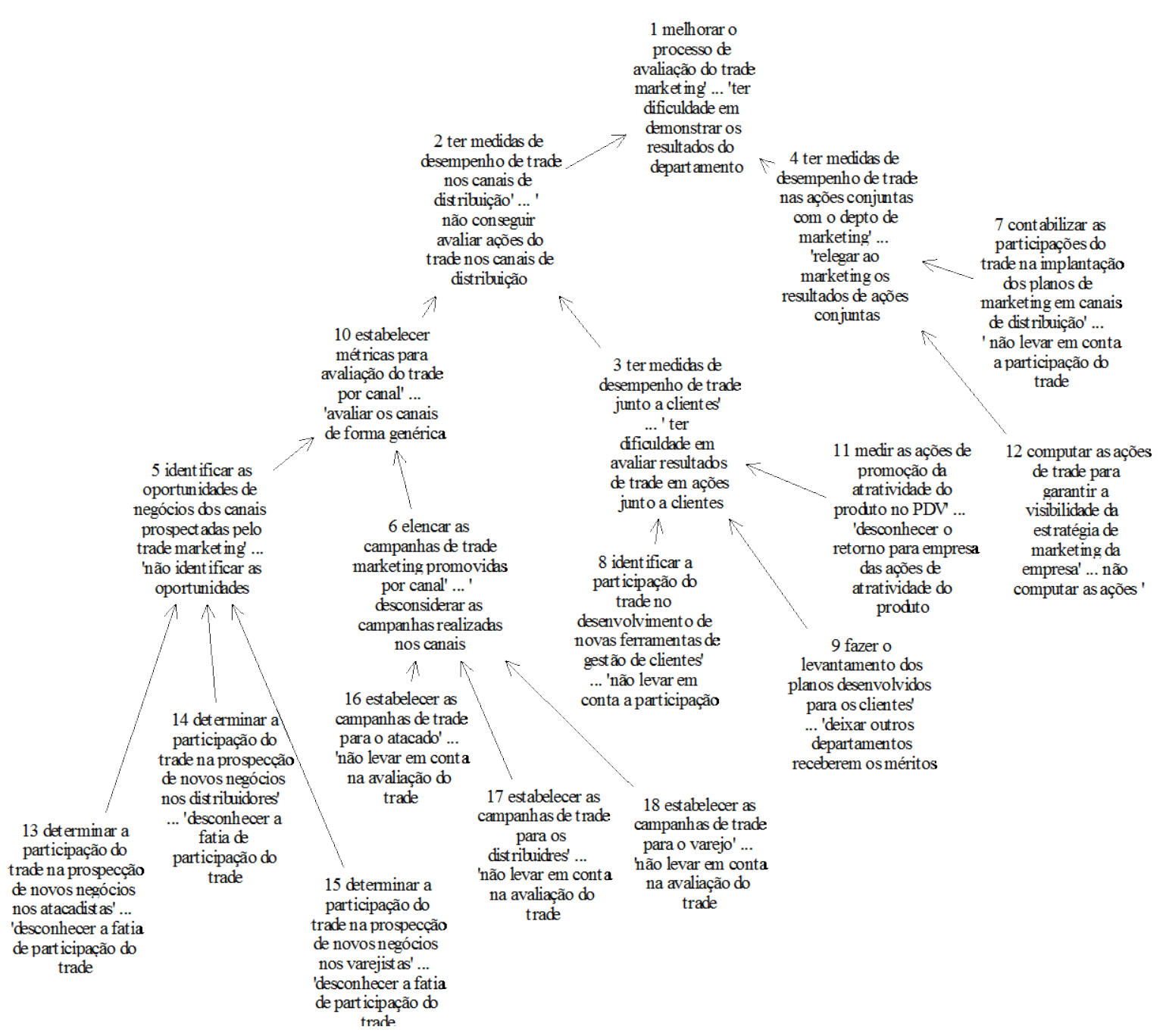

Fonte: Autores

No passo seguinte da etapa de estruturação foi utilizado o conhecimento desenvolvido com o conteúdo dos conceitos e suas relações de influência do mapa cognitivo e adicionado os conceitos de cluster para identificar as áreas e subáreas de preocupação possibilitando a geração de estruturas de relações de hierarquia.

A estrutura dos mapas cognitivos emprega as ligações de influência entre conceitos. Nessas relações, é possível haver apenas um conceito meio para atingir um conceito fim assim como podem haver vários conceitos meios para alcançar um fim. O que não é possível é que um mesmo conceito meio atinja mais de um conceito fim. Nestes casos, isto está a evidenciar que o conceito meio contém mais de uma preocupação e, portanto o conceito meio deve ser desmembrado em suas Revista Produção Online, Florianópolis, SC, v.16, n. 1, p. 49-76, jan./mar. 2016. 
partes constituintes, e assim ao final cada conceito meio alcançará um conceito fim (Ensslin et al., 2013).

Já as estruturas arborescentes dos modelos multicritério utilizam a lógica de decomposição, em que um critério complexo é decomposto em dois ou mais critérios que operacionalizem sua mensuração. Hierarquicamente, um critério de nível superior deve ser explicado pelo conjunto de critérios de nível inferior que o compõem. Além disso, os critérios de nível hierárquico inferior devem ser mutuamente exclusivos e coletivamente prover uma caracterização exaustiva do critério de nível hierárquico superior (KEENEY, 1992; ENSSLIN, MONTIBELLER e NORONHA, 2001).

Para proceder à conversão, empregou-se a técnica do enquadramento de Keeney (1992). Ela foi operacionalizada por meio de quatro fases, todas fundamentadas na análise dos clusters que conformam as áreas de preocupação do mapa cognitivo do estudo de caso. Tais fases consistem em: 1) determinar no mapa onde estão localizados os conceitos que expressam ideias relacionadas aos objetivos estratégicos dos decisores; 2) definir onde estão situados no mapa os conceitos que exprimem ideias associadas às ações potenciais disponíveis no contexto decisório; 3) identificar na estrutura hierárquica do mapa, agrupamentos de conceitos que expressam ideias relacionadas aos possíveis candidatos a critérios do decisor e testá-los; e 4) estabelecer a estrutura hierárquica de valor do processo decisório.

Keeney (1992) sugere que, para um candidato tornar-se efetivamente um critério, seja realizada a análise de suas propriedades. Nesse exame, o candidato a critério deve ser essencial, controlável, completo, mensurável, operacional, isolável, não redundante, conciso e compreensível no âmbito do contexto decisório.

Foram necessárias três entrevistas com os participantes do apoio à decisão para proceder às quatro fases do enquadramento, ao teste dos possíveis candidatos a critérios do modelo e à elaboração da estrutura hierárquica em usa forma definitiva.

A figura 2 expõe a árvore de critérios do modelo. Na parte superior, no nível mais extremo, está o rótulo do modelo, intitulado "avaliar o desempenho do trade marketing". No próximo nível hierárquico têm-se as áreas de preocupação (Ai) "distribuição", "mercado" e "vendas". O nível subsequente descreve os critérios do 
modelo (Cl): "parcerias", "operadores logísticos", "varejo", "share volume", "share receita", "selling out" e "desenvolvimento de clientes".

Figura 2 - Estrutura hierárquica do modelo de avaliação de desempenho do trade marketing do estudo de caso na indústria farmacêutica

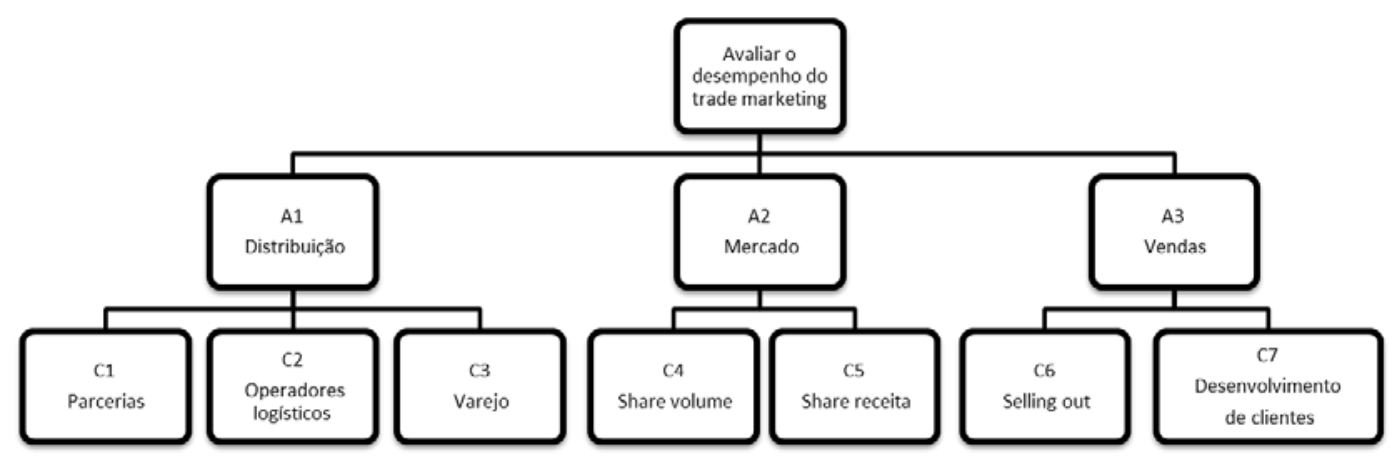

Fonte: Autores

O último passo da etapa de estruturação consistiu na construção de escalas ordinais para cada um dos critérios do modelo. Também chamadas de descritores, as escalas ordinais tem por finalidade permitir que possíveis alternativas possam ter seu desempenho mensurado individualmente em cada critério do modelo.

Para tanto, um descritor deve possuir níveis de impacto, ordenados segundo a preferência percebida pelo decisor, em um processo de comparação par-a-par (ENSSLIN et al, 2010). O nível localizado no extremo inferior da escala representa o pior desempenho e o nível posicionado no extremo superior alude ao desempenho onde tem início os desempenhos em nível de excelência no descritor.

O decisor deve apontar também os níveis neutro (desempenho abaixo do qual o decisor considera comprometedor) e bom (desempenho acima do qual o decisor considera em nível de excelência) do critério.

No estudo de caso em questão, o decisor (coordenador do trade marketing) arbitrou suas preferências nos 28 descritores identificados para o modelo de avaliação do desempenho do trade marketing da indústria farmacêutica.

A figura 3 expõe, a título de ilustração, a estrutura hierárquica dos critérios do modelo com a expansão da área de preocupação "distribuição" do modelo. Apresenta-se o desdobramento do critério C3 (varejo) em seus subcritérios C3.1 (atratividade do produto), C3.2 (espaço físico), C3.3 (selling in) e C.4 (estratégia de preços). No nível mais inferior da estrutura tem-se o subcritério C3.1 desmembrado 
em três escalas ordinais: D7 - $n^{0}$ de ações promocionais por PDV/mês, D8 $-n^{0}$ de multiplicadores por área de abrangência de PDV/mês e, D9 - ciclo de reposição de produtos por PDV/mês. Enfatize-se que as representações dos níveis foram realizadas por números que neste caso são símbolos alfa numéricos e não números do conjunto dos números reais. Assim as escalas são ordinais.

Figura 3 - Escalas ordinais para medir desempenho de uma possível ação no subcritério C3.1 - atratividade do produto

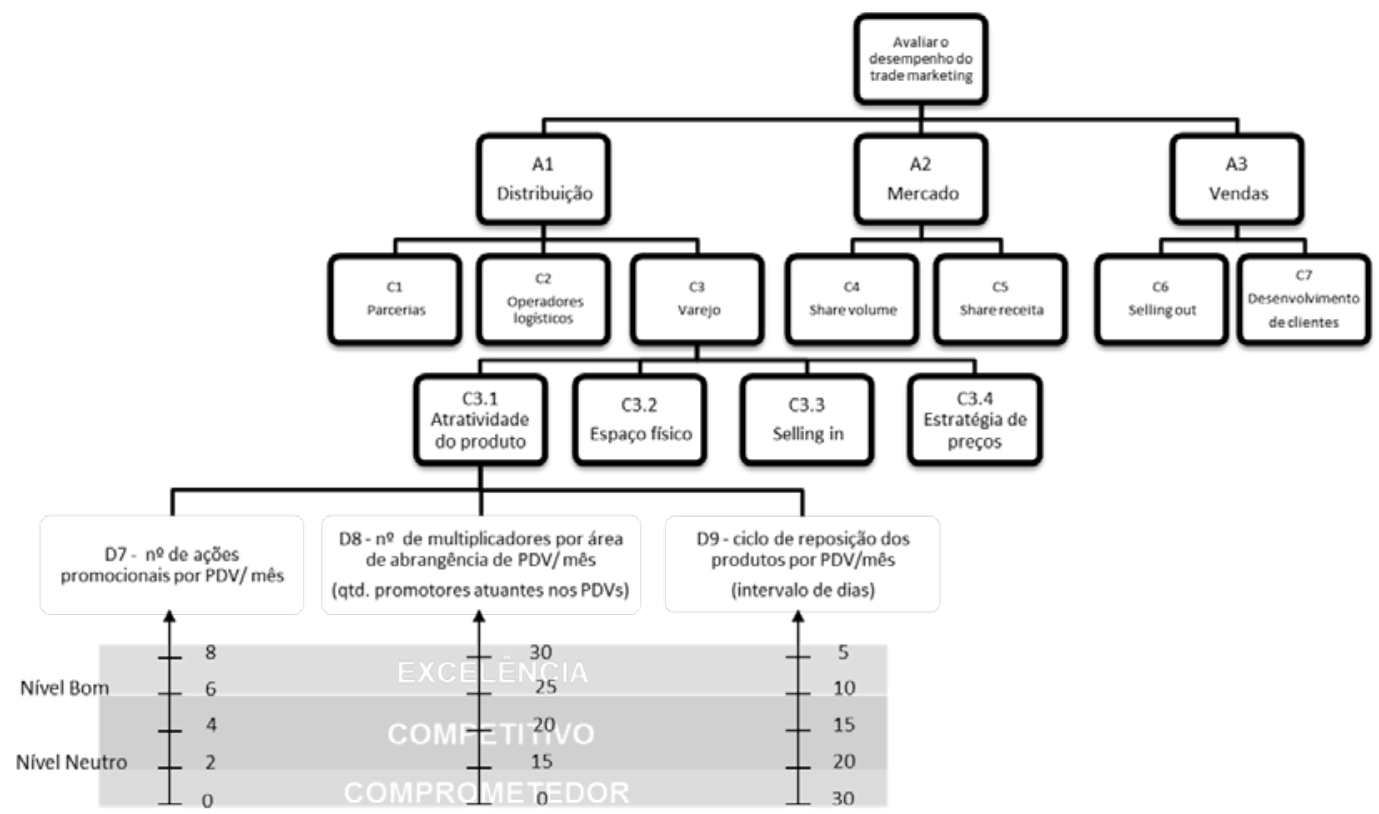

Fonte: Autores

Com o estabelecimento dos descritores para todos os critérios e subcritérios do modelo, a fase de estruturação do processo de apoio à decisão por meio da MCDA construtivista foi concluída. Assim, a consecução da etapa de estruturação proporcionou o conhecimento do contexto decisório, a organização e a hierarquização dos critérios, além da determinação das escalas ordinais do modelo.

\subsection{Etapa de avaliação}

A etapa de avaliação foi realizada através da implementação do modelo no software M-MACBETH, o que auxiliou o decisor a expressar os julgamentos para a construção das funções de valor dos critérios e de suas taxas de compensação, bem 
como da agregação de todos os critérios em único critério geral (BANA E COSTA, DE CORTE e VANSNICK, 2005).

No primeiro passo da etapa de avaliação, foram estabelecidas as funções de valor em cada uma das escalas ordinais. Em uma função de valor importa ao decisor reconhecer o quanto um nível da escala é preferível em relação a outro nível da mesma escala. Essa relação de mensuração da intensidade de preferência é chamada diferença de atratividade e remete a construção de uma escala cardinal intervalar (ROY, 2010).

Preliminarmente, os pesquisadores procederam à inclusão no software de todos os descritores do modelo, bem como à ancoragem do nível neutro (0) e nível bom (100) das escalas.

Após a introdução da descrição de todas as escalas nominais, de seus níveis de impacto e da ancoragem dos níveis bom e neutro no M-MACBETH, os pesquisadores iniciaram o procedimento de identificação das preferências de atratividade locais do modelo de apoio à decisão.

Foram realizadas três entrevistas com o decisor para a obtenção das funções de valor dos 28 descritores do modelo. Tomando por base a matriz de julgamentos semânticos do descritor D9 - ciclo de reposição dos produtos por PDV/mês, por exemplo, os pesquisadores realizaram o seguinte tipo de questionamento à decisora:

\footnotetext{
"Considerando-se que determinada ação potencial impacta no nível N5 (... intervalo de 05 dias para reposição dos estoques de produto por PDV), sendo este nível o mais atrativo, a passagem daí para o nível N4 (... intervalo de 10 dias para reposição dos estoques de produto por PDV) é sentida como uma diferença de atratividade indiferente, muito fraca, fraca, moderada, forte, muito forte ou extrema?"
}

No caso do julgamento descrito, em que se compara a preferência entre passar de um ciclo de reposição de 05 dias (excelente) para outro de 10 dias (bom), a resposta do decisor foi de intensidade moderada.

As respostas do decisor para a comparação entre todos os níveis da escala permitiram o preenchimento completo da matriz de julgamentos semânticos e o calculo da função de valor ancorada para o descritor D9 - ciclo de reposição dos produtos por PDV/mês, conforme apresenta a figura 4. 
Figura 4 - Função de valor para o descritor D9 - ciclo de reposição dos produtos por PDV/mês

D9 - ciclo de reposição dos produtos por PDV/mês

Matriz MACBETH (julgamento das diferenças de atratividade)

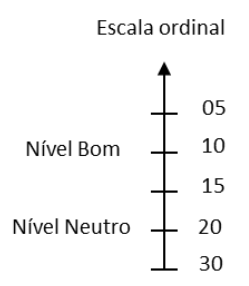

\begin{tabular}{|c|c|c|c|c|c|c|}
\hline & Nivel & N5 & N4 & N3 & N2 & N1 \\
\hline Nivel & dias & 05 & 10 & 15 & 20 & 30 \\
\hline N5 & 05 & & moderada & forte & muito forte & extrema \\
\hline N4 & 10 & & & moderada & moderada & moderada \\
\hline N3 & 15 & & & & moderada & moderada \\
\hline N2 & 20 & & & & & muito fraca \\
\hline N1 & 30 & & & & & \\
\hline
\end{tabular}

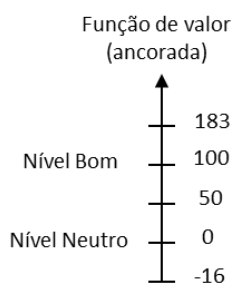

Fonte: Autores

Por meio da analise da figura 4 é possível verificar que a escala cardinal intervalar (função de valor) está normalizada, ou seja, o software realizou uma transformação linear positiva do tipo $f(x)=\alpha x+\beta$ para ancorar os níveis neutro (0) e bom (100) do descritor, e recalcular os demais níveis do descritor.

Com a determinação das funções de valor para todos os descritores, o passo seguinte foi o estabelecimento das taxas de compensação entre os critérios do modelo.

Para tanto, foi utilizado o método MACBETH com a realização de dois procedimentos: a) Criação de ações (Ai) que simulem o impacto nos níveis bom e neutro dos critérios a serem julgados e a ordenação dessas (criação da escala ordinal) por meio da matriz de Roberts (1979); e, b) A inclusão de uma ação potencial fictícia na matriz de julgamentos (estabelecimento de uma ação A0 necessária para que o decisor possa avaliar qual a diferença de atratividade entre passar do nível bom para o nível neutro no critério menos importante e manter-se no nível neutro em todos os demais critérios).

O restante do processo para o cálculo das taxas de substituição seguiu os mesmos pressupostos descritos para as funções de valor.

Nesse sentido, foi realizada uma entrevista, com duração de aproximadamente três horas, em que o decisor expressou seus julgamentos para a obtenção das taxas de substituição do modelo de avaliação de desempenho das atividades do trade marketing da indústria farmacêutica deste estudo de caso. A figura 5 ilustra esse processo para os critérios C1, C2 e C3 do modelo. 
Figura 5 - Processo de determinação das taxas de compensação entre os critérios C1 parceiros, C2 - operadores logísticos e C3 - varejistas

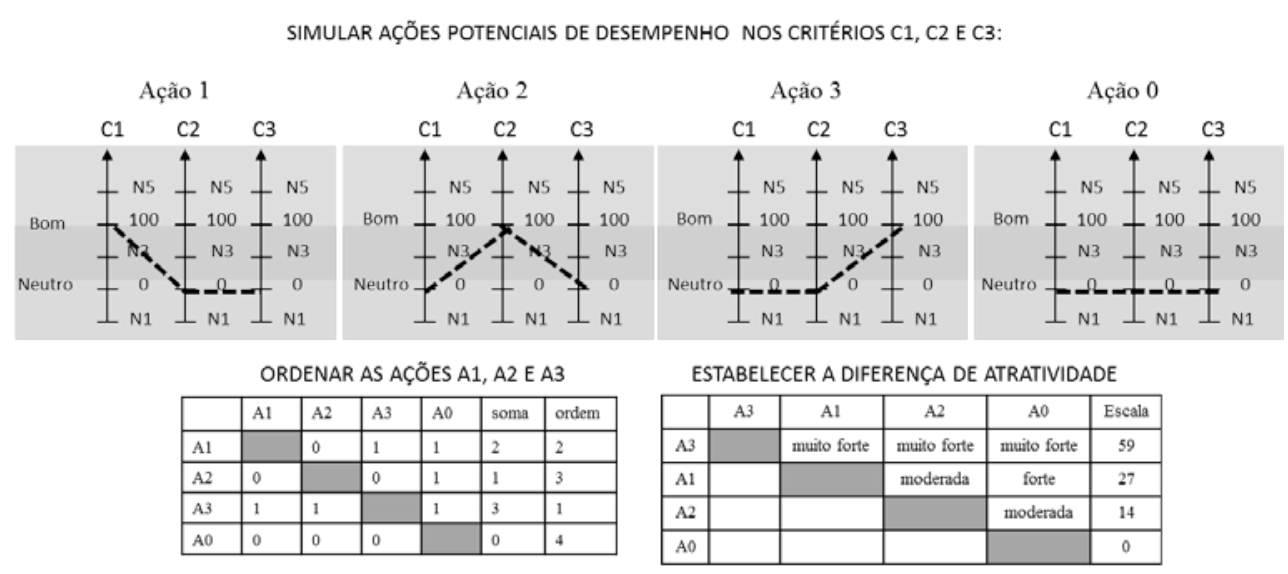

FIXAR AS TAXAS DE SUBSTITUIÇÃO ENTRE OS CRITÉRIOS C1,C2 E C3 NA ESTRUTURA HIERÁRQUICA DE VALORES

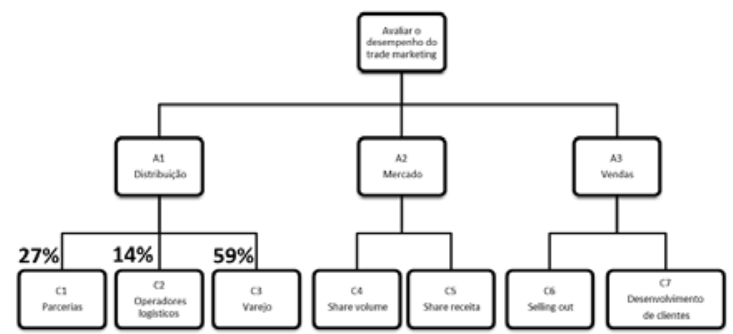

Fonte: Autores

O mesmo procedimento foi empregado para a determinação de todas as taxas de substituição entre os critérios e subcritérios da estrutura hierárquica de critérios.

O último passo da etapa de avaliação diz respeito à agregação todos os critérios do modelo em um único critério geral, que é realizada em duas fases (BANA E COSTA, 1993).

Na primeira fase é feita a agregação dos valores parciais de uma ação em um critério isolado (C) e seus subcritérios (i) por meio da Equação (1):

$V C_{k}(a)=\sum_{i=1}^{n k} w_{i, k} \cdot v_{i, k}(a)$

Onde:

$V_{c k}(a)$ : valor global da ação a do Ponto de Vista $C_{k}$, para $k=1, \ldots m$;

$v_{i, k}(a)$ : valor parcial da ação a no subcritério $i, i=1, \ldots n$, do $C_{k}$, para $k=1, \ldots \mathrm{m}$;

a: nível de impacto da ação a;

Revista Produção Online, Florianópolis, SC, v.16, n. 1, p. 49-76, jan./mar. 2016. 
n: número de critérios do modelo.

Procedidas as agregações das áreas de preocupações, que incorporam os critérios, subcritérios e descritores do modelo, pode-se agregar a performance de uma ação (a) em uma performance única $\mathrm{V}(\mathrm{a})$ usando a Equação (2):

\section{Vglobal $(a)=047$. Vdistribuição $(a)+0.34 \operatorname{Vmercado}(a)+0.19 \operatorname{Vvendas~}(a)$}

Obteve-se, assim, a fórmula global do modelo de apoio à decisão para avaliar as atividades de trade marketing da indústria farmacêutica objeto do estudo de caso. Encerra-se a etapa de avaliação com a finalização da construção do modelo multicritério.

\subsection{Etapa de elaboração das recomendações}

Na MCDA construtivista a etapa de elaboração das recomendações tem o objetivo de apoiar o decisor com o uso do modelo multicritério construído (ROY, 2010). Sugere-se que, inicialmente, seja procedida a verificação do desempenho atual (status quo) nos aspectos em que o modelo desenvolvido se propõe aperfeiçoar (ENSSLIN et al., 2010).

A figura 6 apresenta o perfil de desempenho das atividades do trade marketing identificado pelo decisor logo após o término da etapa de avaliação. 
Figura 6 - Perfil de desempenho das atividades do trade marketing no modelo multicritério construído

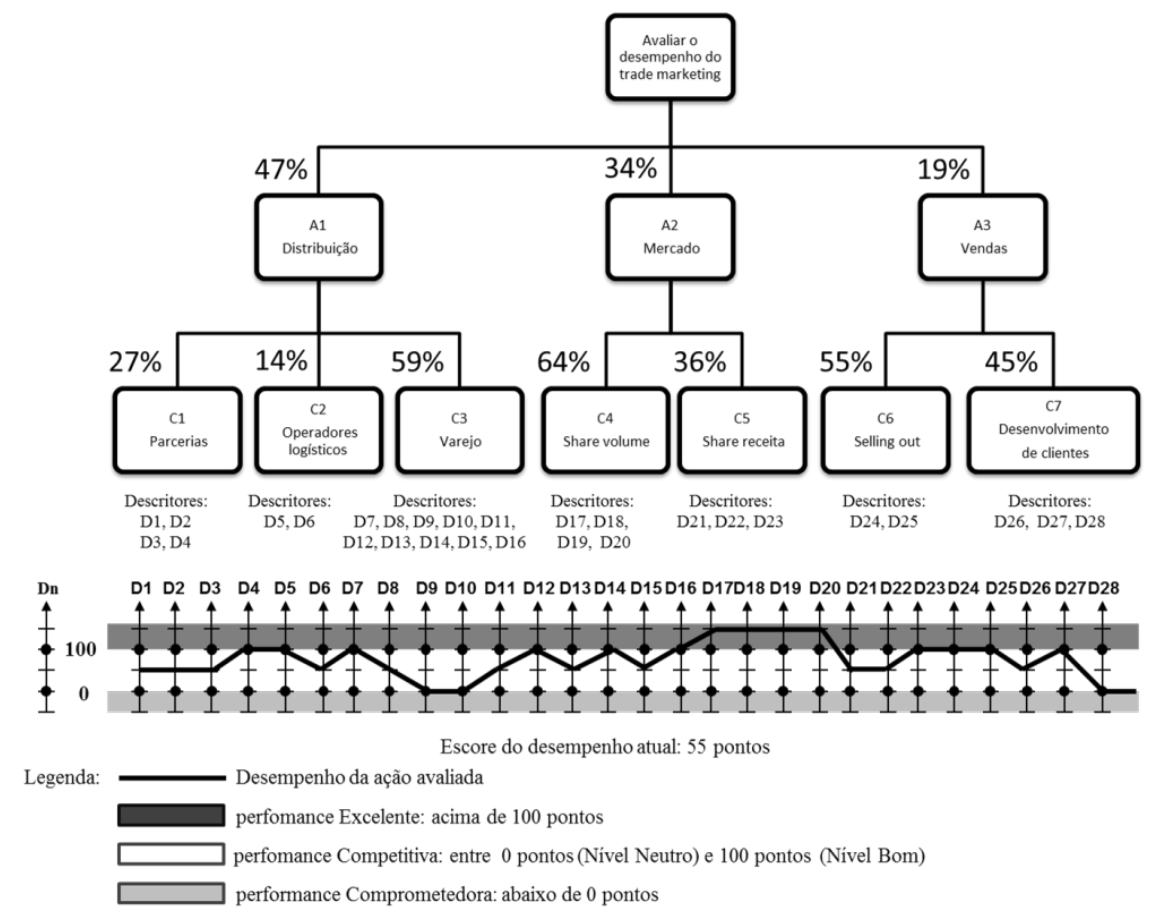

Fonte: Autores

A figura 6 permite verificar que no momento em que foi procedida a avaliação por parte do decisor, apenas o critério C5 - share receita atingiu performance de excelência. Os critérios C1 - parcerias, C2 - operadores logísticos, C4 - share volume, C6 - selling out obtiveram escore na faixa de desempenho competitivo. Já os critérios C3 - varejo e C7 - desenvolvimento de clientes, apresentaram desempenho situado no nível comprometedor na maior parte de seus descritores. $\mathrm{O}$ escore apurado na avaliação global foi de 55 pontos e tem como objetivo servir como parâmetro de comparação com outros possíveis perfis de desempenho.

Com base no perfil de desempenho identificado, o decisor (coordenador do trade marketing) juntamente com os intervenientes (gerente nacional de vendas e gerente nacional de marketing) entendeu ser relevante examinar as causas da baixa performance do critério C3 - varejo.

Por meio da análise vertical da estrutura hierárquica de valores (ver figura 6) verifica-se que o critério C3 - varejo, é integrante da área de preocupação A1 distribuição, que possui taxa de compensação de 47\%, superior às demais áreas de preocupação, A2 - mercado (34\%), e A3 - vendas (19\%). Dentre os critérios 
englobados pela área de preocupação A1 - distribuição, o critério C3 - varejo, detém a maior taxa de compensação (59\%). Os outros critérios, C1 - parcerias e C2 - operadores logísticos possuem taxas de $27 \%$ e $14 \%$, respectivamente.

Desse modo, pode-se constatar que o critério C3 - varejo possui a maior taxa de substituição entre todos os critérios pertencentes à área de preocupação $A 1$, e que essa área detém a maior taxa de substituição dentre todas as áreas do modelo multicritério.

Isso permitiu ao decisor e intervenientes perceberem o quanto A1 e C3 são aspectos sensíveis às variações de perfis de impacto no modelo.

Em outra análise, o exame das escalas cardinais do critério C3 - varejo, demonstra que o baixo desempenho pode ser explicado pelo descritor D9 - ciclo de reposição de produtos PDV/mês e pelo descritor D10 $-n^{\circ}$ de participação como expositores em feiras. Esses descritores possuem no perfil de status quo a performance no menor nível aceitável (neutro).

Para o coordenador de trade marketing o desempenho insatisfatório no descritor D9 é explicado por uma política adotada em 2010 na empresa, em que promotores de trade marketing são promovidos a vendedores (mudam de departamento) sem a devida reposição. Entretanto, quanto menos promoção do trade marketing, menor o número de pedidos de venda e, consequentemente, menor o ciclo de reposição dos produtos no PDV. Tal situação foi exposta ao gerente nacional de vendas na reunião de análise do perfil de desempenho, que afirmou não haver percebido o impacto negativo da nova política adotada e prometeu providências.

No tocante ao descritor D10, a indústria, que possui 65 anos de fundação, não tem cultura de participação em feiras de varejo farmacêutico. Diante disso, o coordenador do trade marketing fez alusão aos resultados do modelo multicritério para demonstrar aos gerentes de vendas e marketing, a importância do investimento para participações em feiras do segmento no âmbito estadual e nacional.

Como a etapa de recomendações da MCDA construtivista não é prescritivista, outras análises podem ser procedidas no modelo multicritério construído, como por exemplo, o exame de robustez das escalas cardinais e a análise de sensibilidade das taxas de compensação. 


\section{CONSIDERAÇÕES FINAIS}

A presente pesquisa, de caráter exploratório, teve por objetivo apoiar as decisões do gestor de trade marketing por meio do desenvolvimento de um modelo de avaliação do desempenho das atividades do departamento de trade marketing de uma indústria farmacêutica. Quanto à natureza, o trabalho se caracterizou como um estudo de caso realizado em uma indústria farmacêutica de grande porte, localizada no Estado do Rio Grande do Sul, e que atua nos segmentos OTC (medicamentos isentos de prescrição médica), fitoterápicos, cosméticos e medicamentos com prescrição médica. Como fonte de coleta de dados, foram realizadas entrevistas não estruturadas para a obtenção dos dados primários e o levantamento de documentos e pesquisa bibliográfica como fonte de dados secundários. O instrumento de intervenção empregado na pesquisa foi a MCDA construtivista. A opção pelo emprego dessa metodologia de apoio à decisão se deveu à sua capacidade de proporcionar condições de identificação, operacionalização e mensuração dos critérios que representam a percepção dos decisores em relação às possibilidades de avaliar o desempenho das atividades de trade marketing da empresa. Viabilizou, ainda, a incorporação de sugestões de melhoria em alternativas com um perfil de desempenho incompatível com o esperado.

O objetivo geral da pesquisa, de construção de um modelo personalizado de avaliação das atividades do trade marketing da empresa foi alcançado por meio da Equação (2), que identificou a fórmula de agregação global do modelo para avaliação de possíveis ações potenciais (alternativas).

Os objetivos específicos foram atingidos no decorrer da elaboração do modelo. Na etapa de estruturação, o uso da abordagem do mapeamento cognitivo possibilitou explicitar os atores do contexto e identificar os aspectos que atendessem as metas de avaliação do trade marketing da empresa. O enquadramento de Keeney (1992) viabilizou a transição do mapa para a estrutura hierárquica de critérios. Na sequência, deu-se a construção das escalas ordinais. Na etapa de avaliação, os pesquisadores empregaram o método MACBETH para transformar as escalas ordinais em escalas cardinais, estabelecer as taxas de compensação entre os critérios, e construir o modelo de agregação dos critérios. Por fim, na etapa de recomendações foi possível representar o perfil de desempenho da situação vigente 
(status quo) no modelo construído e identificar e analisar elementos que merecessem ações de aperfeiçoamento.

O modelo multicritério foi legitimado pelo decisor e intervenientes em todas as fases de sua execução. Ao término de sua elaboração, o decisor obteve uma ferramenta formal para ser usada como instrumento de avaliação de desempenho das atividades do trade marketing, bem como artificio de negociação em questões estratégicas no âmbito da diretoria e conselho da empresa.

O trabalho apresenta como contribuição teórica a capacidade de pormenorizar todas as etapas em que se desenvolve o emprego da MCDA construtivista. Como aporte prático, a pesquisa permitiu ao decisor participar de todas as fases da elaboração do modelo, o que proporcionou maior conhecimento da situação problemática complexa na qual estava inserido e, ao mesmo, trouxe legitimidade ao modelo construído.

Como limitações do trabalho, cita-se, o tempo empregado em entrevistas com o decisor e intervenientes, a necessidade de comprometimento do decisor durante todo o processo de pesquisa e, a singularidade do modelo construído, que não é passível de generalizações. Destaque-se que o processo pode ser replicado em outros contextos, o modelo desenvolvido não, uma vez que foi realizado para atender as condições específicas do ambiente.

A título de sugestão para futuros trabalhos, recomenda-se a utilização da MCDA construtivista para avaliar o desempenho das atividades do trade marketing, do marketing e de vendas, de forma integrada. Outra possibilidade, diz respeito à replicação desta pesquisa em segmento industrial diferente do farmacêutico. Por fim, seria interessante que outros elementos da cadeia de negócios farmacêuticos, como os varejistas ou distribuidores, avaliassem as atividades de trade marketing segundo suas perspectivas.

\section{AGRADECIMENTOS}

Os autores agradecem aos avaliadores anônimos pelas importantes contribuições dadas ao trabalho e ao CNPq pelo financiamento da pesquisa. 


\section{REFERÊNCIAS}

ABRADILAN. Associação Brasileira dos Distribuidores de Laboratórios Nacionais. 2015. Disponível em: < http://www.abradilan.com.br/index.php?m=noticiaFE>. Acesso em: 04 de outubro de 2015.

ALMEIDA, V. ; PENNA, L. ; SILVA, G. ; FREITAS, F. Trade marketing no setor de lojas de conveniências. Revista de Administração de Empresas, v. 52, n. 6, p. 643-656, 2012. http://dx.doi.org/10.1590/S0034-75902012000600006

ALVAREZ, F. J.Trade marketing: estratégias e aplicações. São Paulo: Saraiva, 2008.

BANA e COSTA, C. A. Três convicções fundamentais na prática do apoio à decisão. Revista Pesquisa Operacional, 13, p. 1-12, 1993.

BANA e COSTA, C. A. ; VANSNICK, J. C. Uma nova abordagem ao problema de construção de uma função de valor cardinal: Macbeth. Investigação Operacional, 15, p. 15-35, 1995.

BANA e COSTA, C. A.; DE CORTE, J. M. VANSNICK, J. C. On the mathematical foundations of Macbeth. In: GRECO, J., EHRGOTT, S. (Ed.) Multicriteria decision analysis: state of the art survey. Boston: Springer Verlag, 2005. P. 409-442.

BRIGHTMAN, J. An introduction to decision explorer. New York: Banxia, 2002.

CASTILLO, J. D. Trade marketing. Madrid: Esic Editorial, 2000.

COBRA, M, TALARICO, P. Trade marketing: conceitos \& aplicação. São Paulo: FGV, 2008.

DE MORAES, L. ; GARCIA, R. ; ENSSLIN, L. ; DA CONCEIÇÃO, M. DE CARVALHO, S. The multicriteria analysis for construction of bench markers to support the Clinical Engineering in the Healthcare Technology Management. European Journal of Operational Research, v. 200, n. 2, p. 607-615, 2010. http://dx.doi.org/10.1016/j.ejor.2009.01.018

EDEN, C. Analysing cognitive maps to help structure issues or problems. European Journal of Operational Research, v. 159, n. 3, p. 673-686, 2004. http://dx.doi.org/10.1016/S03772217(03)00431-4.

EDEN, C, ACKERMANN, F. Where next for problem structuring methods? Journal of Operational Research Society, v. 57, n. 7, p. 766-768, 2006.

http://dx.doi.org/10.1057/palgrave.jors.2602090

ENSSLIN, L, MONTIBELLER, G, NORONHA S, M. Apoio à decisão: metodologias para Estruturação de Problemas e Avaliação Multicritério de Alternativas. Florianópolis: Insular, 2001.

ENSSLIN, L, GIFHORN, E, ENSSLIN, S, PETRI, S, VIANNA, W. Avaliação de desempenho de empresas terceirizadas com o uso da metodologia multicritério de apoio à decisão construtivista. Pesquisa Operacional, 30, p. 125-152, 2010.

http://dx.doi.org/10.1590/S0101-74382010000100007 
ENSSLIN, L.; ENSSLIN, S.; ROCHA, S.; MARAFON, A.; MEDAGLIA, T. Multi-criteria decision-aid constructivist model in the supplier evaluation process. Produção, v. 23, n. 2, p. 402-421, 2013. http://dx.doi.org/10.1590/S0103-65132012005000065

Galves, M, L. Structuring Decision Situations: a Brief Overview. In: BARTHĖLEMY, J, P, LENCA, P. (Ed.). Advances in Multicriteria Decision Aid. Enst Bretagne, Brest , 2005. p. $32-40$.

GIL, A, C.Como elaborar projetos de pesquisa. São Paulo: Atlas, 2002.

IBGE.Indicadores da produção industrial por categorias de uso. 2013. Disponível em: < http://ibge.gov.br/home/estatistica/indicadores/industria/pimpfuso atividade/default.shtm >. Acesso em: 04 de outubro de 2015.

KEENEY, R. L. Value-focused thinking: a path to creative decision making. London: Harvard University Press, 1992.

KOTLER, P.; HERMAWAN, K.; IWAN, S. Marketing 3.0: as forças que estão definindo o novo marketing centrado no ser humano. Rio de Janeiro: Campus, 2013.

HUBER, M.; DIPPOLD, K.; FORSTHOFER, R. Which factors drive product sales in OTC markets? International Journal of Pharmaceutical and Healthcare Marketing, v. 6, n. 4, p. 291-309, 2012. http://dx.doi.org/10.1108/17506121211283208

LABAJO, V, CUESTA, P. El Trade marketing: búsqueda de un modelo de colaboración eficiente entre fabricantes y distribuidores. El punto de vista del fabricante. In: Anais del Encuentro de profesores universitarios de marketing, Alicante, Espanha, 2004.

LACERDA, R.T. ; ENSSLIN, L.; ENSSLIN, S. A Performance Measurement Framework in Portfolio Management: A Constructivist Case. Management Decision, 49, p. 1-15, 2011a. http://dx.doi.org/10.1108/00251741111126530

Lacerda, R, T, Ensslin, L, Ensslin, S. A Performance Measurement View Of IT Project Management. The International Journal of Productivity and Performance Management, v. 60 , n. 2, 132-151, 2011b. http://dx.doi.org/10.1108/17410401111101476

Longaray, A, Ensslin, L. Uso da MCDA na identificação e mensuração da performance dos critérios para a certificação dos hospitais de ensino no âmbito do SUS. Production, v. 24, n. 1, p. 41-56, 2014. http://dx.doi.org/10.1590/S0103-65132013005000021

LONGARAY, A, ENSSLIN, L, ENSSLIN, S, ROSA, I. (2015). Assessment of a Brazilian public hospital's performance for management purposes: A soft operations research case in action. Operations Research for Health Care, 5, june 2015, 28-48.

http://dx.doi.org/doi:10.1016/j.orhc.2015.05.001

MOTTA, R, SANTOS, N, SERRALVO, F. (2008) Trade Marketing: teoria e prática para gerenciar os canais de distribuição. Rio de Janeiro: Campus.

ROBERTS, F. (1979) Measurement Theory. In: Encyclopedia of Mathematics and Its Applications. New York: Addison-Wesley Publishing Company.

ROSA, F. S, ENSSLIN, S, R, ENSSLIN, L, LUNKES, R, J. (2012). Environmental Management Disclosure: a construtivist case. Management Decision. 50 (6), 1117-1136. http://dx.doi.org/10.1108/00251741211238364

Revista Produção Online, Florianópolis, SC, v.16, n. 1, p. 49-76, jan./mar. 2016. 
ROSENHEAD, J. Rational analysis for a problematic world: problems structuring methods for complexity, uncertainty, and conflict. Chichester: John Wiley and Sons, 1989.

ROY, B. Multicriteria methodology for decision aiding. Dordrecht: Kluwer Academic Publishers, 1996.

ROY, B. Paradigms and challenges. In: GRECO, J, EHRGOTT, S. (Ed.). Multicriteria decision analysis: state of the art survey (03-24). Boston: Springer Verlag, 2005. p. 3-24.

ROY, B. Robustness in operational research and decision aiding: A multi-faceted issue. European Journal of Operational Research, v. 200, n. 2, p. 629-638, 2010. http://dx.doi.org/10.1016/j.ejor.2008.12.036

Silva Neto, N, Macedo-Soares, T, Pitassi, C. Adequação Estratégica das Áreas de Trade Marketing das Empresas de Bens de Consumo Atuando no Brasil, Revista ADM.MADE, v. 15, n. 1, p. 01-22, 2011. Disponível em < http://revistaadmmade.estacio.br/index.php/admmade/article/viewFile/128/117 >. Acesso em: 04 de outubro de 2015.

Sponton, A, C. A relação fornecedor-cliente: as boas alianças do trade marketing. In: COBRA, M, TALARICO, P. (Ed). Trade marketing: conceitos \& aplicação. São Paulo: FGV, 2008.p. 60-75.

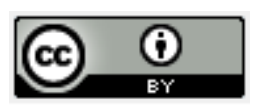

Artigo recebido em 11/09/2014 e aceito para publicação em 04/10/2015 DOI: $\underline{\text { http://dx.doi.org/ 10.14488/1676-1901.v16i1.1885 }}$ 